\title{
CAMA
}

Centre for Applied Macroeconomic Analysis

\section{A note on the impact of the inclusion of an anchor number in the inflation expectations survey question}

\section{CAMA Working Paper 38/2020 April 2020}

\section{Monique Reid}

Department of Economics, University of Stellenbosch

\section{Hanjo Odendaal}

Department of Economics, University of Stellenbosch

\section{Stan Du Plessis}

Department of Economics, University of Stellenbosch

\section{Pierre Siklos}

Wilfrid Laurier University

University of Stellenbosch

Centre for Applied Macroeconomic Analysis, ANU

\section{Abstract}

Inflation expectations surveys are receiving increasing attention. There is no optimal approach and often limited discussion of key characteristics of individual surveys. We use a South African dataset to argue that survey design should be given far more attention as it may undermine our ability to use the data with confidence. Users of survey data need to understand existing differences in survey design and the extent to which survey data reflect decision-making shortcuts under uncertainty as opposed to a true belief about what the public more generally really thinks expected inflation will be. 


\title{
Keywords
}

\author{
JEL Classification
}

\section{Address for correspondence:}

(E) cama.admin@anu.edu.au

ISSN 2206-0332

The Centre for Applied Macroeconomic Analysis in the Crawford School of Public Policy has been established to build strong links between professional macroeconomists. It provides a forum for quality macroeconomic research and discussion of policy issues between academia, government and the private sector.

The Crawford School of Public Policy is the Australian National University's public policy school, serving and influencing Australia, Asia and the Pacific through advanced policy research, graduate and executive education, and policy impact. 


\title{
A note on the impact of the inclusion of an anchor number in the inflation expectations survey question
}

\author{
Monique Reid*, Hanjo Odendaal *, Stan Du Plessis* and Pierre Siklos**1 \\ *Department of Economics, University of Stellenbosch, South Africa \\ **Wilfrid Laurier University, Waterloo, Canada, Research Fellow, University of Stellenbosch, \\ South Africa, and Centre for Applied Macroeconomic Analysis (CAMA)
}

\begin{abstract}
Inflation expectations surveys are receiving increasing attention. There is no optimal approach and often limited discussion of key characteristics of individual surveys. We use a South African dataset to argue that survey design should be given far more attention as it may undermine our ability to use the data with confidence. Users of survey data need to understand existing differences in survey design and the extent to which survey data reflect decision-making shortcuts under uncertainty as opposed to a true belief about what the public more generally really thinks expected inflation will be.
\end{abstract}

\section{Introduction}

Inflation expectations are receiving increased attention. If they are anchored (Woodford 2005) they assist with central bank accountability (Blinder et al. 2008) and improve the efficiency of monetary policy. Expectations are measured either using asset prices (reflecting the expectations of financial markets) or surveys (different social groups). Household surveys are becoming more prominent, because subjective forecasts are 'hard to beat' (Faust and Wright 2013), and survey data capture the expectations of non-financial experts essential to economy-wide price setting behavior.

However, the literature pays limited attention to survey design. Survey design differs across several dimensions, including the social group surveyed, the number of questions, whether the questions are qualitative or quantitative, and the exact phrasing of questions. There is no optimal approach, and limited discussion of key characteristics of individual surveys. As international comparisons of inflation expectations become more commonplace there is also a risk that they measure different things. We argue that some of these choices are crucial to the validity of the data. Given concerns about the anchoring of

1 We thank Hugo Pienaar (Bureau for Economic Research, Stellenbosch) for sharing the data, and acknowledge financial support from the National Research Foundation (Grant number: 93520). 
expectations and ongoing reviews over the appropriate level of inflation central banks should aim for, more attention needs to be paid to survey design.

We are also influenced by the heuristics and biases literature (Tversky and Kahneman, 1974), which has encouraged more rigorous consideration of the use of policy to influence behavior, often in the form of 'nudges' (Thaler and Sunstein 2009). We use South African survey data to explore the provision to respondents of historical inflation data prior to asking their inflation expectations. This is an example of priming (Coibion et al. 2020), which Tversky and Kahneman (1974) argue provides survey respondents with a focal point.

The dataset we use contains two samples which test the effect of the inclusion of an anchor number. Both samples test the inflation expectations of respondents, firstly without providing the historical number, and then with the historical. However, the term inflation ${ }^{2}$, used in Sample A, is replaced with the phrase 'prices in general' in Sample B. The Appendix provides the questions posed. This allows us to test how the provision of prior inflation (prices in general) data influences household respondents' forecasts of inflation. We find that only 28,5\% (28,15\%) of the October 2017 sample kept their answers unchanged when the question included the historical inflation number. This observation is particularly strong for respondents originally deemed 'less rational' (see below) before the provision of historical information.

\section{The validity of survey data}

The Bureau of Economic Research (BER) surveys inflation expectations of households in South Africa (SA) since September 2000, modelled primarily on the University of Michigan survey of consumers. The survey microdata includes sample weights, a procedure often adopted internationally, to allow the sample to be adjusted so that it is representative of the adult, urban and metropolitan population of SA.

Well-created data should be both reliable (measurement should ensure consistency) and valid (the instrument should accurately measure the characteristic of interest, the truth). Market research specialists, AC Nielsen, usually conducts the survey ${ }^{3}$ for the BER, so we assume that the data generated are reliable ${ }^{4}$. Validity is determined by the survey

2 This was the due to the research question of Pienaar (2018), which is not relevant to this paper, but does provide additional data for robustness testing.

${ }^{3}$ For the quarter reported it was AC Nielsen, but there have been a few occasions on which the quarterly data was collected by Ipsos.

${ }^{4}$ A.C. Nielsen aim to ensure that data 'remain constant throughout variations in the measuring process' (Kaplan and Goldsen 1965), by, for example, using a range of welltrained interviewers and interviewing a large, demographically representative sample of 2500 respondents (Nielsen 2017). 
questions themselves, which are designed by the BER. Two criteria along which validity can be assessed are predictive ability (a characteristic that central banks and other analysts are keenly interested in) and the extent to which empirical evidence aligns with theoretical expectations.

Some of the challenges with survey generated data are also identified by Coibion et al. (2020). These include the representativeness of surveys, "priming" of answers, and asking about firm-specific versions of 'inflation' rather than aggregate inflation.

\section{The Anchoring Heuristic}

The anchoring effect is a judgmental heuristic. Tversky and Kahneman(1974) argued that this is used regularly by individuals to reduce the amount of effort required to make decisions under uncertainty. Anchoring emerges when individuals' decisions are influenced by the provision of number that becomes a focal point. A person's final answer to a question is influenced by an initial value, given to them prior to a response. This effect has been found to be surprisingly robust (Furnham and Boo 2011), being identified in both laboratory settings (general knowledge and probably questions) as well as real world settings (such as legal judgements, valuation and purchasing decisions, forecasting, negotiation and self-efficacy).

\section{Does the inclusion of the anchor number influence respondents' forecasts? Evidence from South Africa}

Relying on Pienaar (2018), we consider how the distribution of inflation expectations of the full set of respondents in Sample A differs before (question A4) and after (question A5) the inclusion of the historical inflation number in the survey question. As illustrated in Figure 1 , the inclusion of the anchor appears to have a limited impact when evaluating the full sample - the mean $(\bar{x})$ and standard deviation $(s)$ are reduced modestly, but the median $(\tilde{x})$ is unchanged. In essence, the anchor number causes a small reduction in the variance, but the median expectations remain unchanged. The results for Sample A confirm the robustness of these findings and are available on request. 
Figure 1 Distribution of Expected Inflation responses for full group of respondents
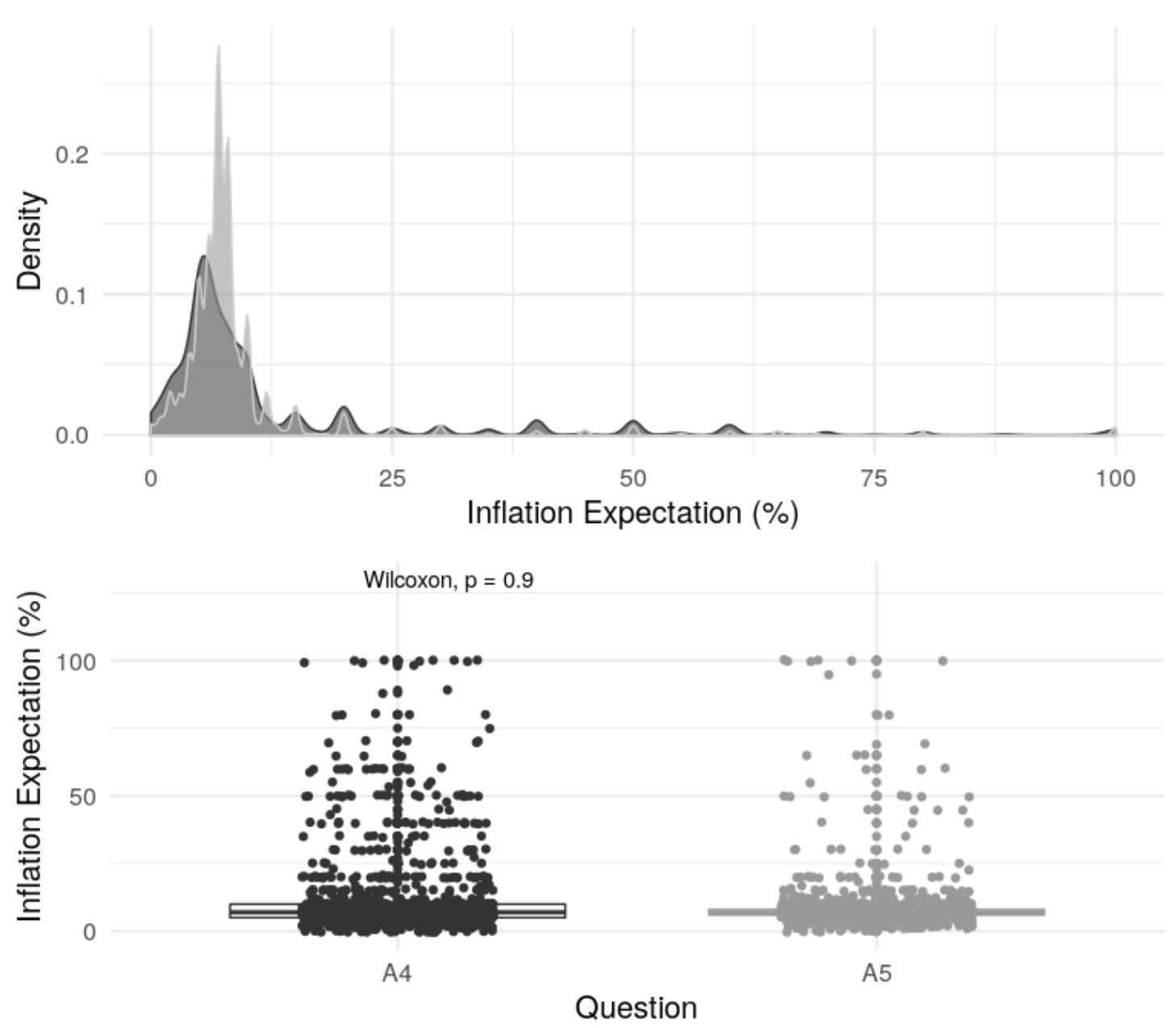

Alternatlve hypothesis: true locatlon shift is not equal to 0

question $\square$ A4 $\square$ A5

Table 1 Descriptive statistics for all respondents

\begin{tabular}{rlllllllllll} 
Variable & $n$ & $\min$ & $q 1$ & $\tilde{x}$ & $\bar{x}$ & $q 3$ & $\max$ & $s$ & IQR & \#NA \\
\hline A4 & 1083 & 0 & 5 & 7 & 12.7 & 10 & 100 & 16.6 & 5 & 192 \\
A5 & 1176 & 0 & 6 & 7 & 9.0 & 8 & 100 & 10.5 & 2 & 99
\end{tabular}


However, these aggregate numbers hide valuable information. We split the samples into a group whose expectations before the inclusion of the anchor number were more realistic $(<10 \%)$ versus those that were less realistic $(>10 \%)$, and we compare the extent of anchoring effect within each of these groups. The 10\% threshold is selected because $90 \%$ of the estimates are below $10 \%$ for the inflation expectations questions. Hence, the responses above $10 \%$ (unrealistic forecasts) are treated as outliers ${ }^{5}$.

Once the sample is divided into more realistic responses before the historical inflation is supplied versus the less realistic ones, the absence of uniformity becomes quite clear. The responses of the more realistic respondents are influenced only modestly by the inclusion of the anchor number in the question ${ }^{6}$, while those of the less realistic respondents change dramatically (see Figure 2). The descriptive statistics in Table 2 show that the provision of the anchor number affects both the median and variance of the group of respondents that was less realistic to begin with.

To formally test this difference, a non-parametric Wilcoxon test is performed, which confirmed that the inflation expectations were significantly different with $\mathrm{p}<0.01$ and moderate effect size $r=0.726$ for sample B and $\mathrm{p}<0.01$ and $r=0.765$ for sample A, as shown in the bottom portion of Figure 2 .

${ }^{5}$ See (Reid, Siklos and Du Plessis, 2019) for a discussion on different thresholds and the motivations for them.

${ }^{6}$ Results available upon request. 
Figure 2 Distribution of Expected Inflation responses for respondents with expectations $>10 \%$
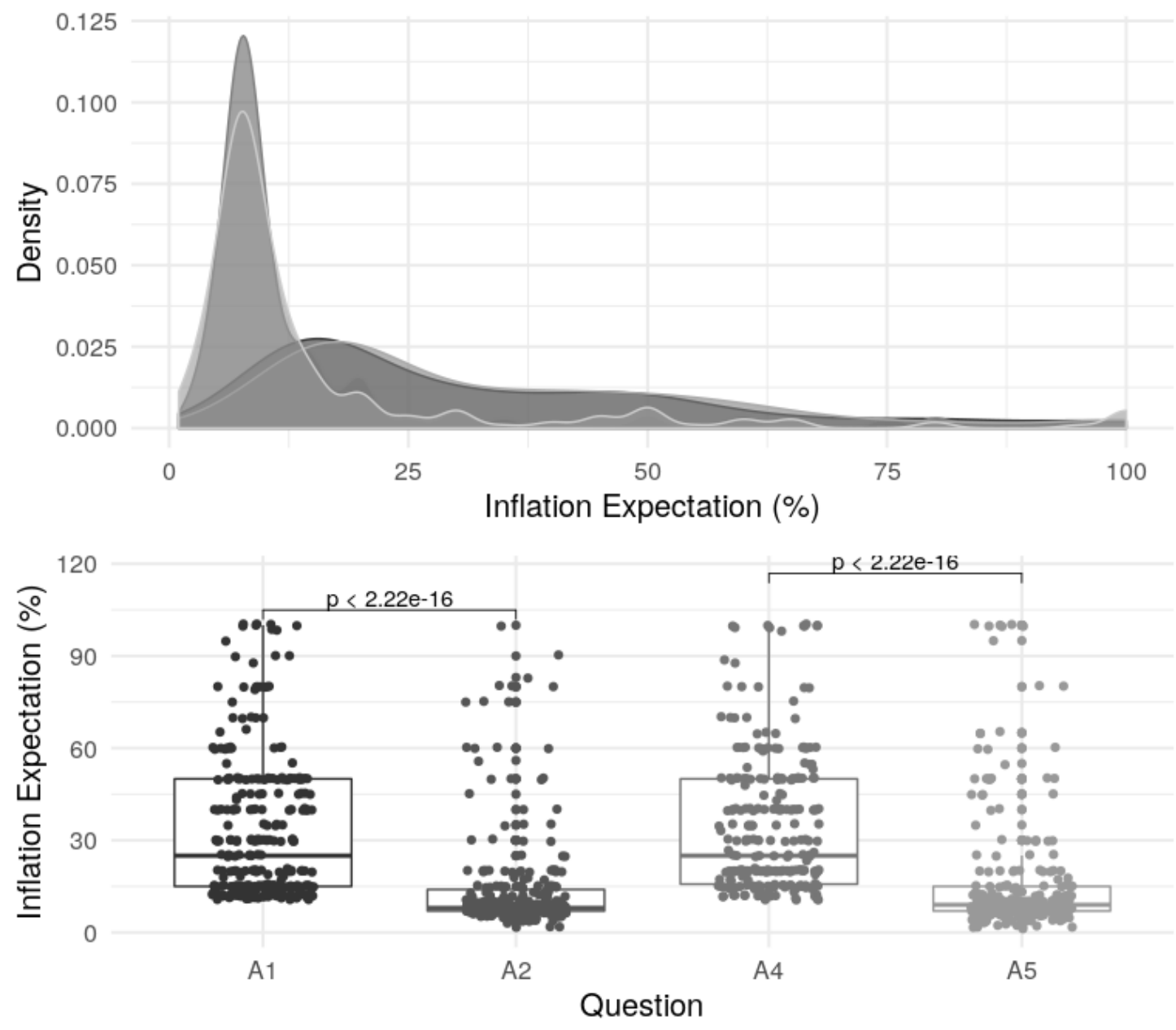

Alternative hypothesis: true locatlon shift is not equal to 0 question $\square$ A1 $\square$ A2 $\square$ A4 $\square$ A5

Table 2 Descriptive statistics for less rational respondents

\begin{tabular}{r|llllllllll} 
Variable & $n$ & $\min$ & $q 1$ & $\tilde{x}$ & $\bar{x}$ & $q 3$ & $\max$ & $s$ & $I Q R$ & \#NA \\
\hline $\mathrm{A} 1$ & 277 & 11 & 15.0 & 25 & 33.1 & 50 & 100 & 23.2 & 35.0 & 0 \\
\hline $\mathrm{A} 2$ & 271 & 2 & 7.0 & 8 & 14.5 & 14 & 100 & 16.3 & 7.0 & 6 \\
\hline
\end{tabular}




\begin{tabular}{l|llllllllll} 
A3 & 256 & 11 & 15.8 & 25 & 34.7 & 50 & 100 & 22.6 & 34.2 & 0 \\
A4 & 251 & 1 & 67.0 & 9 & 16.3 & 15 & 100 & 20 & 8.0 & 5
\end{tabular}

\section{Conclusions}

Since CPI inflation in SA was 6.3\% in 2016 and averaged 5.4\% over the preceding five years, we considered respondents who expected inflation rates of $10 \%$ or more to have unrealistic inflation expectations. Against this backdrop, we find that the provision of historical inflation in the survey question biases expectations in the direction of past observed inflation outcomes, consistent with Tversky and Kahneman's (1974) anchoring effect. Hence, if households are provided with advance information, some will take shortcuts when deciding what they believe next year's inflation rate will be. The broader implications of our results are two-fold. First, as empirical exercises containing inflation expectations survey data have mushroomed, users of survey data need to understand existing differences in survey design. Second, if communicating information in a credible manner influences how respondents feel about future inflation, central banks and other analysts need to better understand the extent to which survey data reflect decision-making shortcuts under uncertainty as opposed to a true belief about what the public more generally really thinks expected inflation will be.

\section{APPENDIX: QUESTIONS}

Question A1: By about how much do you expect prices in general to increase during the next 12 months?

Question A2: Over the past five years prices increased by on average 5.4 per cent per year. During 2016, prices increased by 6.3 per cent. + Question A1

Question A4: What do you expect the rate of inflation to be during the next 12 months?

Question A5: Over the past five years, the rate of inflation was 5.4 per cent per year. During 2016, the rate of inflation was 6.3 per cent. + Question A4

\section{References}

Blinder, Alan S, Michael Ehrmann, Marcel Fratzscher, Jakob De Haan, and David-Jan Jansen. 2008. "Central Bank Communication and Monetary Policy: A Survey of Theory and Evidence." Journal of Economic Literature 46(4): 910-45.

Coibion, Olivier, Yuriy Gorodnichenko, Saten Kumar, and Mathieu Pedemonte. 2020. "Inflation Expectations as a Policy Tool?" Journal of International Economics. Elsevier, 103297. 
Faust, Jon, and Jonathan H Wright. 2013. "Forecasting Inflation." In Handbook of Economic Forecasting, 2:2-56. Elsevier.

Furnham, Adrian, and Hua Chu Boo. 2011. "A Literature Review of the Anchoring Effect." The Journal of Socio-Economics 40(1). Elsevier: 35-42.

Hothorn, Torsten, Kurt Hornik, and Achim Zeileis. 2006. "Unbiased Recursive Partitioning: A Conditional Inference Framework." Journal of Computational and Graphical Statistics 15 (3). Taylor \& Francis: 651-74.

Kaplan, Abraham, and Joseph M Goldsen. 1965. "The Reliability of Content Analysis Categories." Language of Politics: Studies in Quantitative Semantics. MIT Press Cambridge, 83-112.

Levene, Howard. 1961. "Robust Tests for Equality of Variances." Contributions to Probability and Statistics. Essays in Honor of Harold Hotelling. Stanford University Press, 279-92.

Nielsen, A. C. 2017. Nielsen Omnibus Technical Specifications.1-9.

Pienaar, H. 2018. "Re-Assessing the South African Household Inflation Expectations Survey Through a Sequential Mixed Methods Approach." Unpublished Masters Thesis. Stellenbosch University.

Reid, M., Siklos, P., and Du Plessis, S. (2019), "What Drives Household Inflation Expectations in South Africa? Demographics and Anchoring Under Inflation Targeting", unpublished (earlier version available as CAMA working paper 48/2019).

Thaler, Richard H, and Cass R Sunstein. 2009. Nudge: Improving Decisions About Health, Wealth, and Happiness. Penguin.

Tversky, Amos, and Daniel Kahneman. 1974. "Judgment Under Uncertainty: Heuristics and Biases." Science 185 (4157). American association for the advancement of science: 112431.

Woodford, Michael. 2005. "Central Bank Communication and Policy Effectiveness." National Bureau of Economic Research. 